Case Report

\title{
Coronally advanced flap as a root coverage procedure in treatment of class I gingival recession defects-A report of two cases
}

\author{
Anahita Punj ${ }^{1}$, Amitha Ramesh ${ }^{2}$ \\ ${ }^{1}$ Postgraduate, ${ }^{2}$ Professor, Department of Periodontology, A.B. Shetty Memorial Institute of Dental Sciences, Nitte \\ University, Deralakatte, Mangalore.
}

*Corresponding Author : Anahita Punj, Post Graduate, Department of Periodontology, A.B. Shetty Memorial Institute of Dental Sciences, Nitte University, Deralakatte, Mangalore-575018, Karnataka, India. $\quad$ Mobile : +91 $9686991954 \quad$ E-mail : anahitapunj@gmail.com

$\begin{array}{ll}\text { Received } & : 18.07 .2016 \\ \text { Review Completed } & : 14.01 .2017 \\ \text { Accepted } & : 05.02 .2017\end{array}$

Keywords : Recession, Coronally advanced flap, Root coverage

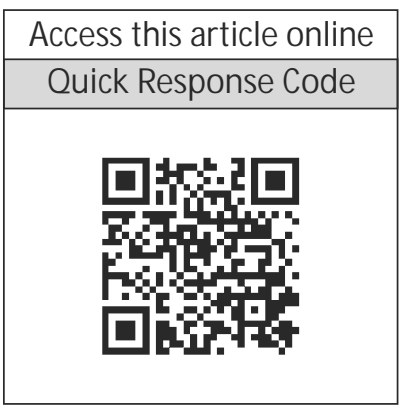

\begin{abstract}
Gingival recession is defined as the apical migration of the gingival margin beyond the cementenamel junction (CE)). This results in the exposure of tooth roots which is aesthetically unpleasing and can also result in tooth hypersensitivity. A number of surgical procedures have been used to obtain root coverage. The aim of the present article was to evaluate the coverage of labial gingival recession defects with coronally advanced flap procedure in two cases with labial gingival recession.

Two male patients ( 32 year and 52 year old) were treated for root coverage with coronally advanced flap in maxillary right first molar (16), second premolar (15) and maxillary left incisor (22) and canine (23) region respectively.

In both the cases, root coverage of the labial recession defects was observed.
\end{abstract}

\section{Introduction}

Gingival recession is defined as the apical displacement of the gingival margin with respect to the cement-enamel junction (CE)). ${ }^{1}$

There a number of etiological factors leading to gingival recession such as inflammatory periodontal disease, trauma from faulty tooth brushing, occlusal trauma, high frenal attachment, tooth malposition or root prominence leading to the thinning of bony plate, orthodontic tooth movement in unusual direction, underlying alveolar dehiscence, thin gingival biotype etc. ${ }^{2}$

From a patient's point of view gingival recession not just gives an unsightly appearance from an aesthetic point of view but also can lead to patient discomfort if it results in dental hypersensitivity or root caries. ${ }^{3}$

Root coverage procedures have been in practice to cover the denuded root surfaces to provide aesthetic benefit to the patient and relieve and prevent dental hypersensitivity. ${ }^{2.3}$

There are various surgical procedures for root coverage mentioned in the dental literature, with each procedure having its own advantage, limitation, indication and feasibility. These include: free gingival graft, coronally advanced flap, subepithelial connective tissue graft, pedicle flap, semilunar flap, transpositional flap, connective tissue pedicle graft, guided tissue regeneration etc. 4,5

The coronally advanced flap procedure has been used since long as an aesthetic root coverage procedure and as a treatment modality for tooth sensitivity arising as a result of gingival recession. It is a simple procedure among all the root coverage procedures with various modifications. ${ }^{2,3}$ 
This article aims to study the success of coronally advanced flap procedure for covering labial gingival recession defects.

\section{Case Presentation}

Case 1

A 33 year old male patient reported to the department of Periodontics, A.B. Shetty Memorial Institute of Dental Sciences, Deralakatte, Mangalore for routine cleaning of teeth. On examination, the patient had Miller's Class I gingival recession defect with recession depth (RD) of 5 $\mathrm{mm}$ in the maxillary right first molar (16) and $2 \mathrm{~mm}$ (RD) Class I gingival recession defect in maxillary right second premolar (15). Recession depth (RD) was measured from the most apical part of the gingival margin to the cementenamel junction with a periodontal probe.

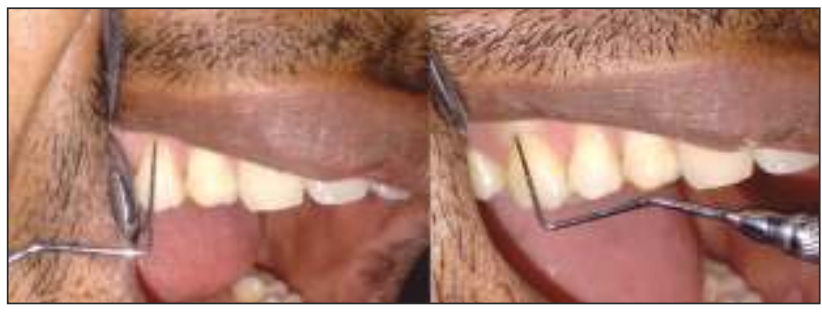

The patient also gave a history of mild hypersensitivity in the same teeth after drinking cold water. The gingival recession was caused due to faulty tooth brushing by the patient as he gave a history of using a hard brush for brushing teeth with horizontal motion. Patient was a nonsmoker and systemically healthy.

As a result, the tooth brushing habit of the patient was corrected by instructing and educating the patient to use a soft bristle brush with modified bass technique of tooth brushing.

After keeping the patient on regular follow up and maintenance visits, root coverage of 16, 15 with Coronally Advanced Flap was planned. The procedure was chosen as the patient had an adequate width of attached gingiva and to avoid a second surgical (donor) site which is required in graft procedures like free autogenous grafts and free connective tissue grafts.

Informed consent was obtained from the patient after thorough explanation of the risks and benefits of the clinical procedure planned.

Local anaesthetic, $2 \%$ lignocaine hydrochloride containing adrenaline at aconcentration of 1:80,000 was used. On the buccal aspect of the tooth involved intra-sulcular incision was made starting from mesial line angle of 17 till distal line angle of 14 by using Bard parker number 15 blade (B.P.Blade).

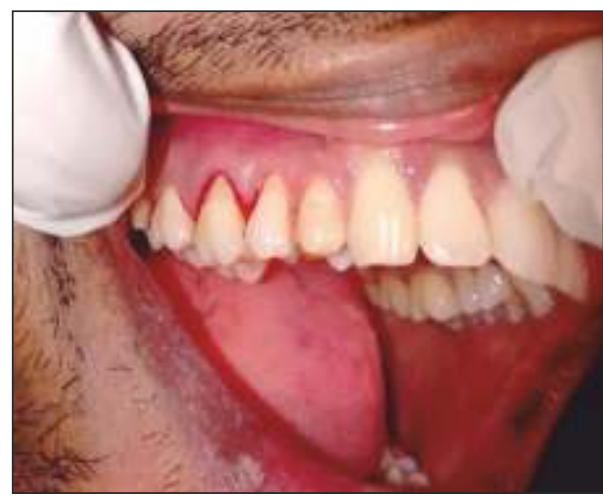

A full-thickness flap was reflected using a periosteal elevator till the mucogingival junction. Next, the sulcular incision was extended apically beyond the mucogingival junction to obtain a split thickness flap beyond the mucogingival junction. Finally, a full- split thickness flap was elevated which allowed passive coronal positioning of the flap. The root surface was instrumented with curettes and irrigated with sterile normal saline solution. Composite stops (composite placed at the contact points of teeth and cured) were placed over the teeth to aid in suturing and maintaining the new position of the raised flap. The tissue flap was advanced coronally, adjusted to the prepared recipient bed for optimal fit, and secured by suturing the flapat the level of the CEJ to the connective tissue bed in the papilla regions by interrupted sutures ( 3.0 black silk suture material) over the composite stops. The operated area was secured with a periodontal pack.

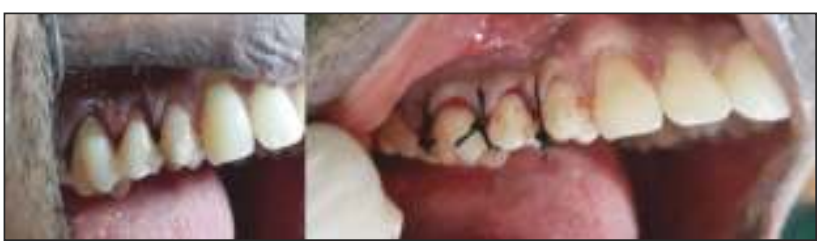

Patient was instructed to avoid tooth brushing particularly in the surgical area for 4 weeks, but chemical plaque 
control was maintained by $0.12 \%$ chlorhexidine mouthwash in dosages of $10 \mathrm{ml}$ for 1 minute twice a day for 2 weeks after the procedure.

Furthermore, analgesics were prescribed for 3 days (Tab. Diclofenac $50 \mathrm{mg}$ b.d). Patient was instructed to report to the department in case of any discomfort following surgery.

Surgical sutures and pack were removed after 6 days. The area was irrigated with sterile normal saline.

Three weeks after the surgery, the patient was instructed to resume tooth brushing in the treated area using soft bristled toothbrush.

Postoperative examination at 1 week and 4 weeks showed root coverage with respect to 16,15 .

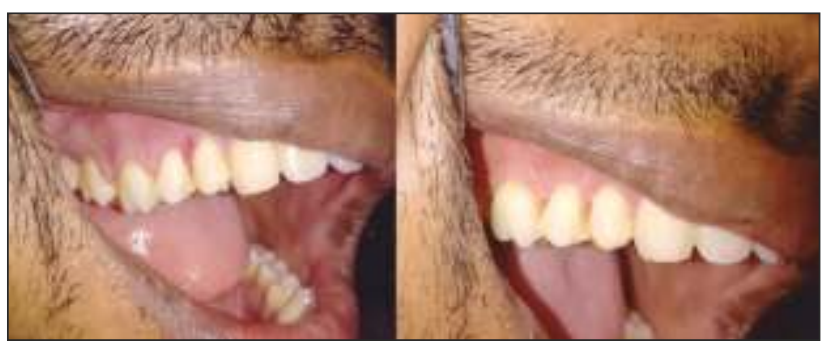

\section{Case 2}

A 52 year old male patient reported to the department of Periodontics, A.B. Shetty Memorial Institute of Dental Sciences, Deralakatte, Mangalore for routine cleaning of teeth. On examination, the patient had $3 \mathrm{~mm}$ (RD) Miller's Class I gingival recession in the maxillary left lateral incisor (22) and $5 \mathrm{~mm}$ (RD) M iller's Class I gingival recession defect in maxillary left canine (23).

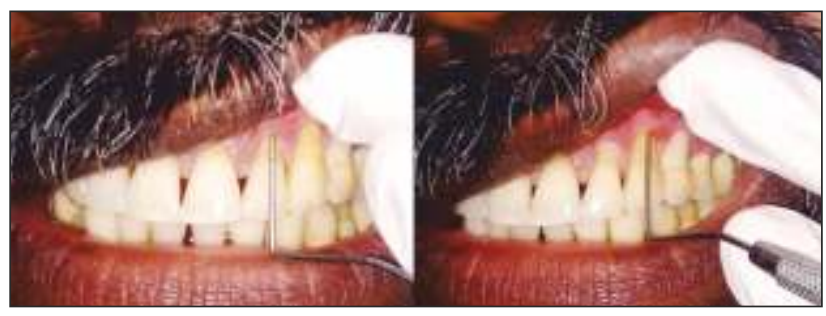

After keeping the patient on regular follow up and maintenance visits, root coverage of 22, 23 with coronally advanced flap was planned.

Patient was a non-smoker, systemically healthy and had no contraindications for periodontal surgery.

Similar surgical procedure as in case 1 was performed which involved raising a full-split thickness flap extending from distal line angle of 21 to mesial line angle of 24 .

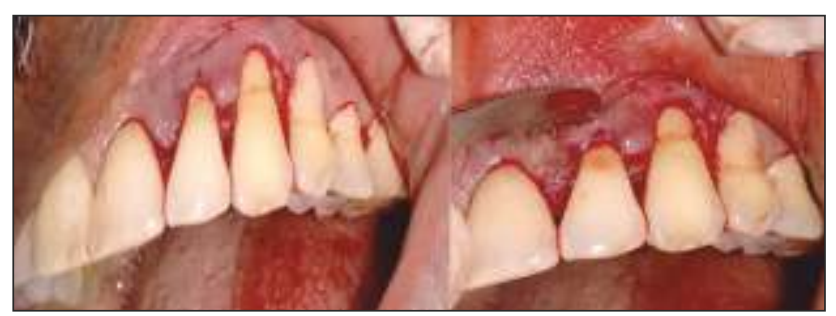

The tissue flap was advanced coronally, adjusted to the prepared recipient bed for optimal fit, and secured by suturing the flap at the level of the CEJ to the connective tissue bed in the papilla regions by two sling sutures (3.0 black silk suture material). The operated area was secured with a periodontal pack.

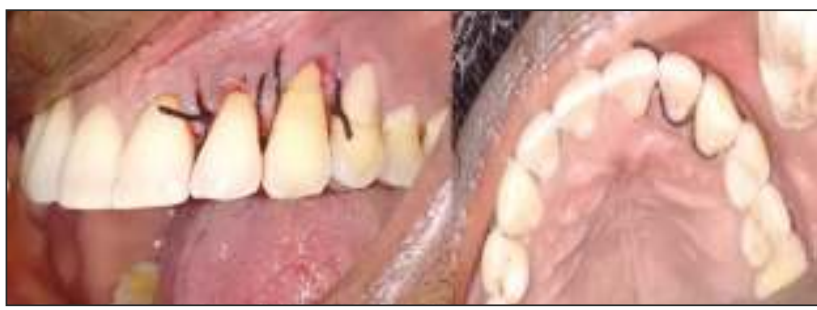

Postoperative examination after 8 days showed root coverage with respect to 22,23 .

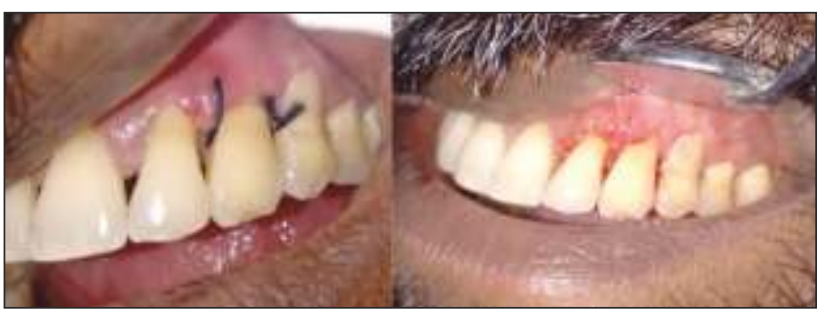

Postoperative examination after 1 month showed partial root coverage with respect to $22,23$.

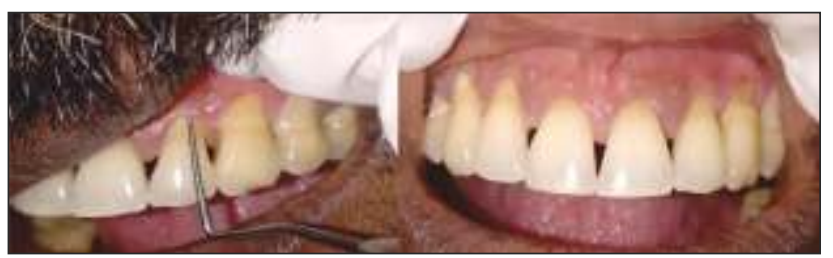

\section{Discussion}

Gingival recession causes exposure of the root surfaces of 
teeth making them exposed to the harsh oral environment. Following exposure of the roots, the patients may develop dental hypersensitivity due to the exposure of the dentinal tubules which are in contact with the dental pulp. Prolonged root exposure can also predispose the tooth to root caries or other wasting diseases. ${ }^{6}$

The management of gingival recession involves diagnosing the etiology of recession followed by surgical correction if the recession continues to progress or is of aesthetic concern to the patient. ${ }^{7}$

The success of the coverage of these defects depends on the type of recession, depth and width of recession to be covered, tooth position, thickness of keratinsed gingiva etc.

P.D Millers ${ }^{8}$ has classified the recession into class I, II, III and IV. Classes I and II gingival recession shows $100 \%$ success rate to root coverage procedures, Class III shows 50 to $70 \%$ success, and Class IV shows only 0 to $10 \%$ success. ${ }^{9}$ Studies have shown that greater baseline recession depths were always associated with decreased complete root coverage $^{10,11}$

Sullivan and Atkins have classified gingival recession as Shallow - Narrow, Shallow - Wide, Deep - Narrow and Deep. The defects can be classified as shallow $(<3 \mathrm{~mm})$, moderate (3-5mm) or deep (>5mm). ${ }^{12}$

The size of the defect in both vertical and horizontal directions should be considered. It is assumed that larger the recession area, less the root coverage will be expected. ${ }^{13}$

Norberg (1926) introduced coronally positioned flap procedure. The Coronally positioned flap is one of the valid surgical options in the treatment of M illers class I and class Il gingival recession.

Millers Class I recessions, with a mean initial recession height of 3-4 $\mathrm{mm}$ can be treated with pedicle soft tissue grafts, free soft tissue grafts or combinations of the two. Among the pedicle grafts, the coronally advanced flap is the commonly been used as a means of gaining root coverage and has varying degree of success. It is one of the valid surgical options to cover exposed root surfaces.

Advantages of this technique over other surgical procedures for treating gingival recession are: it does not require a separate surgical site to obtain a graft, it has perfect color/contour match with the surrounding tissue, the procedure is not technique sensitive, thus making it simple to perform. It does not require an extended surgical or recovery time. The results are stable overtime. Limitations of this technique include the need for adequate width of attached gingiva and adequate depth of vestibule. $^{15}$

M ost of the studies support the hypothesis that therapy with coronally advanced flap alone can be successfully applied when the residual gingiva is thick and wide. Accordingly, the adjunctive use of a graft could be restricted to sites with thin and narrow residual gingiva. ${ }^{10}$

In the cases discussed here, the coronally advanced flap was raised without giving vertical incisions to prevent additional suturing and to prevent compromising the vascularity of the flap making the procedure minimally invasive. Here, similar protocol for coronally advanced flap without vertical incision ${ }^{6,16}$ was followed in both the cases, but the suturing technique varied, i.e., sling sutures were placed in case 1 , while in case 2 , sutures were placed over composite stops.

In case 1 recession depth was reduced from $5 \mathrm{~mm}$ to $1 \mathrm{~mm}$ in 16 and $2 \mathrm{~mm}$ to 0 in 15, while in case 2 recession depth was reduced from $3 \mathrm{~mm}$ in 22 to $1 \mathrm{~mm}$ and $5 \mathrm{~mm}$ to $2 \mathrm{~mm}$ in 23. The results obtained here are in accordance with study done by PiniPrato et al. ${ }^{17}$ that showed coronally advanced flap was effective in the treatment of single gingival recession, but apical shift of the gingival margin occurred in $53 \%$ of the cases and was associated with a reduction of keratinised tissue probably because the patient resumed traumatic brushing habit.

The amount of root coverage as assessed by the reduction in recession depth was lesser in case 2 as compared to case 1 , probably due to the thinner gingival biotype of the 
patient as compared to the patient in case 1 . These results are in accordance with the fact that thin biotype has an influence on the amount of root coverage obtained post surgically. ${ }^{18}$

In another study, Pini Prato et al reported that the gingival margin, sutured, on average, $1 \mathrm{~mm}$ coronal to the cemento-enamel junction, remained stable at week 1 , but shifted apically from 2 to 4 weeks, uncovering of the cemento-enamel junction occurred in $60 \%$ of the sites with an average shift of $1.5 \pm 0.6 \mathrm{~mm}$. Postoperatively, after 4-12 weeks after the procedure, the gingival margin remained stable. ${ }^{19}$

The limitations of this case report are the short follow up

\section{References}

1. Glossary of Periodontal terms. 4th ed. Chicago: American Academy of Periodontology; 2001. American Academy of Periodontology; p. 44

2. Zucchelli G, Mounssif I et al. Periodontal plastic surgery. Periodontology 2000, 2015; 68: 333-368

3. Deswal H, Singh Y, M unjal A, Grover H.S. Coronally Advanced Flap For The Treatment Of Gingival Recession In Molars: A Clinical Case International Journal of Medical Science and Clinical Invention. 2016; 3(1): 1521-1523

4. Pradeep K, Rajababu P, Satyanarayana D,Sagar V. Gingival Recession: Review and Strategies in Treatment of Recession. Case Reports in Dentistry. 2012; 1-6

5. American Academy of Periodontology. Oral Reconstructive and Corrective Considerations in Periodontal Therapy. J Periodontol 2005 76: $1588-1600$

6. Zucchelli G, De Sanctis M. Treatment of multiple recession type defects in patients with aesthetic demands. J Periodontol 2000;71:1506-1514

7. Merijohn G.K. Management and prevention ofgingival recession. Periodontology 2000. 2016; 71:228-242

8. Miller PD. A classification of marginal tissue recession. Int Periodontics Restorative Dent. 1985; 5: 8-14.

9. Tarnow DP. Semilunar Coronally Repositioned Flap. ClinPeriodontol.1986:13:182-5.

10. Roccuzzo M, Bunino M, Needleman I, Sanz M. Periodontal plastic surgery for treatment of localized gingival recessions: a systematic review. Journal of Clinical Periodontology.2002:29:178-194,

11. Clauser C, Nieri M, Franceschi D, Pagliaro U, Pini Prato GP. Evidence based mucogingival therapy. Part 2: Ordinary and individual patient time period (4 weeks) and no comparisons, with the other root coverage procedures.

\section{Conclusion}

Thustechnique of coronally advanced flap is reliable for the treatment of gingival recession as root coverage was observed in both the cases. The advantage of using this technique for root coverage was no post-operative discomfort, good blood supply, good color matching, stable result and resolution of dentinal hypersensitivity.

This case report indicates that teeth with multiple gingival recessions, associated with toothbrush trauma can be successfully treated by the coronally advanced flap.

data meta-analyses of surgical treatment of recession using complete root coverage as the outcome variable.J Periodontol. 2003;74:741-56

12. Sullivan H. C, Atkins J. H "Free autogenous grafts. Utilization of grafts in the treatment of gingival recession" Periodontics 1968; 6; 152-160

13. Ozturan S. Treatment of Gingival Recession with Coronally Advanced Flap Procedure. International Journal of Basic and Clinical Studies (IJBCS) 2013;2(2): 153-159.

14. Kavitha J, Navarasu M, Srikanth V. Treatment of Gingival Recession Using Coronally Advanced Flap - Case Reports. International Journal of Dental Sciences and Research. 2014;2(1):1-4.

15. Vincent J, "Root Coverage techniques", Periodontal abstracts. 1995 43.

16. Zucchelli G, Mele M, Mazzotti C, Marzadori M, Montebugnoli L, De Sanctis M. Coronally Advanced Flap With and Without Vertical Releasing Incisions for the Treatment of M ultiple Gingival Recessions: A Comparative Controlled Randomized Clinical Trial. J Periodontol 2009:80:1083-1094

17. Pini-Prato G, Franceschi D, Rotundo R Cairo F,Cortellini P, Nieri M. Long-Term 8-Year Outcomes of Coronally Advanced Flap for Root Coverage. J Periodontol 2012;83:590-594.

18. Huang LH, Neiva REF, Wang HL. Factors Affecting the Outcomes of Coronally Advanced Flap Root Coverage Procedure. J Periodontol 2005:76:1729-1734.

19. Pini Prato G, Clauser C, Cortellini P, Tinti C, Vincenzi G, Pagliaro U. Guided tissue regeneration versus mucogingival surgery in the treatment of human buccal recessions. A 4-year follow-up study. Journal of Periodontology. 1996;67:1216-1223. 